East African Medical Journal Vol. 86 No. 3 March 2009

GASTRO-DUODENAL PEPTIC ULCER PERFORATION

J. C. B. Dakubo, BSc, MBChB, FWACS, S. B. Naaeder, MBChB, (UG), FRCS (Edin), FWACS, FGCS and J. N. Clegg-Lamptey,

MBChB, FRCS (Edin), FWACS, FGCS, University of Ghana Medical School, P. O. Box 4236, Accra, Ghana

Request for reprints to: Dr. J. C. B. Dakubo, University of Ghana, Medical School, P. O. Box 4236, Accra, Ghana

\title{
GASTRO-DUODENAL PEPTIC ULCER PERFORATION
}

\author{
J. C. B. DAKUBO, S. B. NAAEDER and J. N. CLEGG-LAMPTEY
}

\begin{abstract}
Objectives: To determine the epidemiology of, and define the morbidity and mortality factors following emergency surgery for patients with perforated peptic ulcer disease in Accra, Ghana.

Design: A retrospective and prospective hospital-based study.

Setting: The general and paediatric surgical wards of the Korle-Bu Teaching Hospital.

Main outcome measures: Demography, the systolic BP, pulse rate and haemoglobin on admission at ER, co-morbid conditions, site of perforation, surgical method and treatment outcome.

Subjects: A total of 326 cases treated for peptic ulcer perforation, 267 males and 59 females; ratio 4.5:1, with mean age of 40.9, SD 16.4 and range 4-87 years, were studied.

Results: The incidence of peptic ulcer perforation rose from $1.6 \%$ in 1998 to $5.3 \%$ in 2002 and stabilised at $5 \%$, and overall accounted for $4.6 \%$ of acute abdomen. Co-morbid conditions were present in $48(18.2 \%)$ of cases. Ulcerogenic substance intake was in $177(67 \%)$ patients. One hundred and twenty two $(46.2 \%)$ patients reported to hospital within 24 hours of perforation. There were $287(88 \%)$ duodenal, $22(7.1 \%)$ prepyloric, and $19(4.9 \%)$ type 1 gastric ulcer perforations. Simple closure with omental patch was performed in $299(94.3 \%)$, truncal vagotomy and drainage in $10(3.2 \%)$, and Billroth II partial gastrectomy in seven $(2.2 \%)$. Post-operative complications occurred in $62(19 \%)$; overall mortality was $36(\mathbf{1 1} \%)$. Logistic regression analysis of the patients clinical variables showed that age less that 60 years ( $p$-value, OR and $95 \% \mathrm{CI}$; 0.002, 3.964 and 1.668-9.420), duration of perforation of more than 24 hours before admission (p-value, OR and $95 \% \mathrm{CI} ; 0.011,2.471$ and 1.228-4.971), alcohol intake (p-value, $\mathrm{OR}$ and $95 \% \mathrm{CI}$; $0.009,2.543$ and 1.259-5.135) and resectional surgery (p-value, OR and $95 \% \mathrm{CI} ; 0.000$, 8.25E and 74204908.138-9162648048.1) were statistically significant in determining postoperative complications. Age 60 years and above (p-value, OR and $95 \% \mathrm{CI} ; 0.018,4.359$ and 1.284-14.802), alcohol intake (p-value, $O R$ and $95 \% \mathrm{CI} ; 0.042,3.238$ and 1.046-10.021) and resectional surgery ( $\mathrm{p}$-value, $\mathrm{OR}$ and $95 \% \mathrm{CI}$; 0.000, 1.20E and $938112920.94-1.54 \mathrm{E}+$ 11) were the factors that showed statistical significance in determining post-operative mortality.

Conclusion: Perforated peptic ulcer disease is emerging as a frequent cause of acute abdomen in our centre and affects the youth commonly. Age 60 years and above, duration of perforation for more than 24 hours before admission, alcohol intake and resectional surgery were the variables that showed statistical significance in predicting post-operative morbidity and/or mortality.
\end{abstract}

\section{INTRODUCTION}

Perforated gastro-duodenal peptic ulcer disease remains a frequent clinical problem and is potentially fatal. Following improvements in sanitation, introduction of effective anti-acid secreting drugs and eradication of Helicobacter pylori (H. pylori) infection with antibiotics in dyspeptic patients, the incidence of perforated gastro-duodenal peptic ulcer disease has decreased worldwide (1). Even though the frequency of perforated peptic ulcer disease is decreasing overall among all ages, it is, however, becoming more frequent among old people and women (1-3) who acquired their H. pylori infection 
earlier in life, are on regular ulcerogenic drugs such as steroids and anti-inflammatory drugs, or who smoke $(1,2,4,5)$.

The incidence of perforated gastro-duodenal pepticulcer disease in developing countries appears to be rising and affects young people $(6,7)$. It is a frequent cause of acute abdomen in Ghana (8-10). In Korle$\mathrm{Bu}$ Teaching Hospital (KBTH), Accra, surgery for perforated pepticulcer is performed as an emergency procedure mostly by surgical trainees who usually close the perforation by the omental patch method followed by $H$. pylori eradication and suppression of acid secretion with a proton pump inhibitor.

Since the recognition of Helicobacter pylori by Marshall and Warren in 1983 (11) as an important pathogenic agent in peptic ulcer disease and the subsequent changing trends in the treatment of this condition and its complications the world over, the problem of perforated gastro-duodenal peptic ulcer disease has largely not been examined in Ghana and some countries in Africa. This study was therefore undertaken to assess the epidemiology of perforated peptic ulcer disease in Accra, Ghana. It also assessed the main determinants of early morbidity (postoperative complications) and mortality following emergency surgery for perforated peptic ulcer. The influence of the patients' clinical characteristics, location of the perforation and the surgical technique employed on post-operative complications and deaths were analysed.

\section{MATERIALS AND METHODS}

Patients treated for gastro-duodenal peptic ulcer perforation over a nine year period (July 1998 to June 2007) at the KBTH were studied. It was both a retrospective (July 1998 to June 2003) and prospective (July 2003 to June 2007) study.

The data on the patientsin the retrospective group were obtained from the theatre and recovery ward registers, the admissions and discharges registers on the four general surgical wards and the patients' case notes retrieved from the medical archives and medical records departments of the hospital.

Information obtained from the registers included the age, sex, location of perforated ulcer, type of surgery performed, and the treatment outcome (usually mortality). Additional data that were extracted from the patient's records were occupation, duration of perforation before presentation, substance (Non-Steroidal AntiInflammatory Drugs (NSAIDS), alcohol, smoking, steroids) use, previous dyspepsia or peptic ulcer symptoms, the physiological indices of the patients on arrival at the emergency room, the haematological and biochemical test results as well as post-operative complications.

For the prospective study group, one of the authors (JCBD) interviewed the patients on the third or fourth day after their operation to obtain accurate clinical data and monitored them till they were discharged to the outpatient's clinic for follow up. The medical records of these patients were also reviewed a month after discharge to document complications. All data relevant to the study were recorded on a form designed for this study.

The causes of the deaths that occurred within 30 days of surgery were obtained from the mortuary register.

\section{RESULTS}

Figure 1 shows the annual frequencies of peptic ulcer perforations seen at the Korle-Bu Teaching Hospital. There were a total of 326 cases, 157 retrospective and 169 prospective. There were 267 males and 59 females; ratio $4.5: 1$, (Table 1$)$. The mean age (SD, range) of the patients was $40.9(16.4,4-87)$ years. The mean ages (SD, range) were, for males $40.3(16.1,4-80)$ years and for females $43.6(17.2,11-87)$ years.

Figure 1

Annual frequencies of patients treated for perforated peptic ulcer

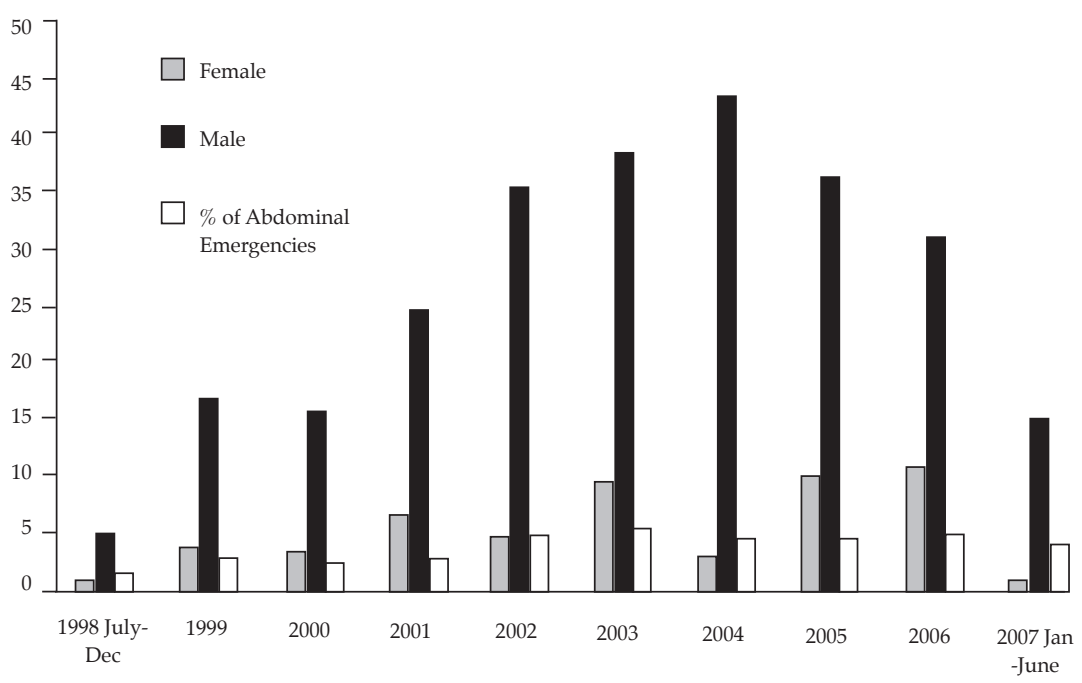


There was a progressive rise in the incidence of perforated peptic ulcer disease as a cause of nontraumatic acute abdominal condition from $1.6 \%$ in the second half of 1998 to $5.3 \%$ in 2002 and remained above $5 \%$. Overall, perforated peptic ulcer accounted for $4.6 \%$ of non-traumatic acute abdomen that required surgery. The peak age incidence of perforation was in the $20-49$ year age group. Perforation was less common before age 20 years of age $21(6.4 \%)$ cases, and after 70 years, $20(6.1 \%)$ patients.

The disease afflicted mainly people of low socioeconomic standing in our society: traders $18.4 \%$, artisans of all trades $12.6 \%$, porters $12 \%$, drivers $7.4 \%$, students $7.1 \%$, pensioners $6.7 \%$ and the unemployed $4.9 \%$ were the majority (Table 2).

A previous history of dyspepsia or peptic ulcer symptoms was absent in 120 out of 264 patients (45.5\%); (Table 3). Twenty eight (10.6\%) patients had experienced dyspepsia for less than three months before the perforation. One hundred and sixteen (43.9\%) patients suffered dyspepsia for more than three months. Of the 144 patients who had dyspepsia $85(59 \%)$ did not report for definitive diagnostic evaluation whilst $51(35.4 \%)$ patients were treated empirically. The diagnosis prior to perforation was confirmed in only eight $(5.6 \%)$ of the cases.

Table 1

Age, sex distribution

\begin{tabular}{|c|c|c|c|c|c|c|c|c|c|c|}
\hline \multirow{2}{*}{$\begin{array}{l}\text { Age } \\
\text { (years) }\end{array}$} & \multirow[b]{2}{*}{$\mathrm{M}$} & \multirow[b]{2}{*}{$\mathrm{F}$} & \multicolumn{4}{|c|}{ Retrospective } & \multicolumn{2}{|c|}{ Prospective } & \multicolumn{2}{|c|}{ Overall } \\
\hline & & & Total & $(\%)$ & $\mathrm{M}$ & $\mathrm{F}$ & Total & $(\%)$ & Total & $(\%)$ \\
\hline $0-9$ & 2 & 0 & 2 & 1.3 & 1 & 0 & 1 & 0.6 & 3 & 0.9 \\
\hline $10-19$ & 8 & 2 & 10 & 6.4 & 6 & 2 & 8 & 4.7 & 18 & 5.5 \\
\hline $20-29$ & 25 & 4 & 29 & 18.5 & 33 & 4 & 37 & 21.9 & 66 & 20.2 \\
\hline $30-39$ & 33 & 7 & 40 & 25.5 & 38 & 5 & 43 & 25.4 & 83 & 25.5 \\
\hline $40-49$ & 24 & 11 & 35 & 22.3 & 23 & 6 & 29 & 17.2 & 64 & 19.6 \\
\hline $50-59$ & 14 & 0 & 14 & 8.8 & 19 & 6 & 25 & 14.8 & 39 & 12.0 \\
\hline $60-69$ & 15 & 3 & 18 & 11.5 & 11 & 4 & 15 & 8.9 & 33 & 10.1 \\
\hline $70-79$ & 6 & 0 & 6 & 3.8 & 5 & 2 & 7 & 4.1 & 13 & 4.0 \\
\hline $80-89$ & 2 & 1 & 3 & 1.9 & 2 & 2 & 4 & 2.4 & 7 & 2.1 \\
\hline Total & 129 & 28 & 157 & 100.1 & 138 & 31 & 169 & 100 & 326 & 99.9 \\
\hline
\end{tabular}

Table 2

Occupation

\begin{tabular}{lccll}
\hline Occupation & Retrospective & Prospective & Total & $(\%)$ \\
\hline Trader & 20 & 40 & 60 & 18.4 \\
Porter & 14 & 25 & 39 & 12.0 \\
Artisan & 11 & 30 & 41 & 12.6 \\
Driver & 10 & 14 & 24 & 7.4 \\
Student & 8 & 15 & 23 & 7.1 \\
Retired from active work & 11 & 11 & 22 & 6.7 \\
Unemployed & 5 & 11 & 16 & 4.9 \\
Farmer & 6 & 3 & 9 & 2.8 \\
Officer Status & 3 & 6 & 9 & 2.8 \\
Beauticians & 2 & 4 & 6 & 1.8 \\
Teacher & 2 & 2 & 4 & 1.2 \\
Fisherman & 0 & 3 & 3 & 0.9 \\
Housewife & 1 & 2 & 3 & 0.9 \\
Domestic service & 1 & 1 & 2 & 0.6 \\
Musician & 0 & 1 & 1 & 0.3 \\
Clerk & 0 & 1 & 1 & 0.3 \\
Prisoner & 1 & 0 & 1 & 0.3 \\
Data not available & 62 & 0 & 62 & 19.0 \\
\hline Total & 157 & 169 & 326 & 100.6 \\
\hline
\end{tabular}


Table 3

History of previous dyspepsia or peptic ulcer symptoms

\begin{tabular}{lcccc}
\hline Duration & Retrospective & Prospective & Total & $(\%)$ \\
\hline None & 49 & 71 & 120 & 45.5 \\
$<3$ months & 8 & 20 & 28 & 10.6 \\
3months-1 & year 11 & 25 & 36 & 13.6 \\
$>$ 1 year & 27 & 53 & 80 & 30.3 \\
\hline Total & 95 & 169 & 264 & 100 \\
\hline
\end{tabular}

Forty eight patients out of $264(18.2 \%)$ had associated co-morbid conditions. Systemic hypertension was the most frequent medical condition ( 24 cases) followed by diabetes mellitus (seven cases). Detailed in Table 4 are the associated conditions that were present in the study population.

Table 4

Chronic medical illness or co-morbid conditions

\begin{tabular}{lcccc}
\hline Condition & Retrospective & Prospective & Total & $(\%)$ \\
\hline Hypertension & 5 & 19 & 24 & 7.4 \\
Diabetes mellitus & 1 & 6 & 7 & 2.1 \\
Cirrhosis & 1 & 2 & 3 & 0.9 \\
Asthma & 0 & 3 & 3 & 0.9 \\
Cancer of larynx & 0 & 1 & 1 & 0.3 \\
Oesophageal cancer & 0 & 1 & 1 & 0.3 \\
Sickle cell disease & 0 & 2 & 2 & 0.6 \\
Chronic anaemia & 0 & 3 & 3 & 0.9 \\
Post surgery & 2 & 2 & 4 & 1.2 \\
Recent assault & 0 & 1 & 1 & 0.3 \\
Chronic urine retention & 0 & 2 & 2 & 0.6 \\
BPH & & & & \\
Chronic leg ulcer & 0 & 1 & 1 & 0.3 \\
CCF & 0 & 1 & 1 & 0.3 \\
Tuberculosis & 0 & 1 & 1 & 0.3 \\
Below knee amputation & 0 & 1 & 1 & 0.3 \\
Rheumatoid arthritis & 0 & 1 & 1 & 0.3 \\
\hline
\end{tabular}

$\mathrm{BPH}=$ Benign prostate hypertrophy, $\mathrm{CCF}=$ Congestive cardiac failure

A history of regular ingestion of NSAIDS was obtained from $126(47.7 \%)$ patients. Regular alcohol consumption $93(35.2 \%)$, smoking $30(11.4 \%)$ and steroid usage three $(1.1 \%)$ were the other ulcerogenic substances taken by patients in this study. In all $177(67 \%)$ of patients were taking these substances either singly or in combinations.

One hundred and twenty two $(46.2 \%)$ patients reported to hospital within 24 hours of perforation,
(Table 5) with only $23(8.7 \%)$ reporting in less than 12 hours. The rest were seen after 24 hours.

Table 5

Duration of perforation

\begin{tabular}{lcccc}
\hline Duration & Retrospective & Prospective & Total & $(\%)$ \\
\hline Up-to 12 hours & 4 & 19 & 23 & 8.7 \\
1 day & 45 & 54 & 99 & 37.5 \\
2 days & 17 & 27 & 44 & 16.7 \\
3 days & 13 & 29 & 42 & 15.9 \\
$>3$ days & 16 & 40 & 56 & 21.2 \\
\hline Total & 95 & 169 & 264 & 100 \\
\hline
\end{tabular}

Chest X-ray was done in stable patients to identify pnuemoperitonium and to evaluate the lung fields. Of the 103 patients who were subjected to this investigation only six $(5.8 \%)$ did not demonstrate gas under the diaphragm. A wide range of clinical diagnoses was made in patients with perforated peptic ulcer. A correct diagnosis of perforated peptic ulcer was made in $155(58.7 \%)$ patients. Typhoid ileal perforation $40(15.2 \%)$ and acute/ruptured appendicitis $38(14.4 \%)$ were the next most frequent diagnoses made (Table 6).

Of the 316 patients who were treated surgically $299(94.3 \%)$ had simple omental patch closure of the perforation. Truncal vagotomy and drainage was performed on ten $(3.2 \%)$ patients and Billroth II partial gastrectomy was undertaken in the remaining seven (2.2\%) patients. Therewere287(88\%) duodenal, 23(7.1\%) prepyloric and $16(4.9 \%)$ type 1 gastric perforations. Gastric carcinoma was excluded from all prepyloric and type 1 gastric perforations by histopathological examination of the excised ulcer edge in this study.

Seventy three $(27.7 \%)$ patients developed postoperative complications. Chest infection, septicaemia, and abdominal wound infection were the mostcommon complications followed by leakage of the closed perforation and intra-abdominal sepsis (Table 7).

There were $36(11 \%)$ deaths overall, 13 in the retrospective and 23 in the prospective groups. Ten patients $(3.1 \%)$ died while being resuscitated for surgery. The mean age of those who died was 52.5 years; 26 males and 10 females (ratio, 2.6:1) with respective mean ages of 52.8 and 51.8 years. Twelve $(33.3 \%)$ of them presented within 24 hours of the perforation, $20(55.6 \%)$ used one or more ulcerogenic substance regularly and $16(44.4 \%)$ had co-morbidity. A correct diagnosis was made in $19(52.8 \%)$ patients and surgery was performed on $26(72.2 \%)$. Endotoxic shock from sepsis was the major cause of death followed by bronchopneumonia (Table 8). 
Table 6

Clinical diagnosis at initial assessment

\begin{tabular}{lcccc}
\hline Diagnosis & Retrospective & Prospective & Total & $(\%)$ \\
\hline Perforated DU & 55 & 100 & 155 & 58.7 \\
Acute/ruptured appendix & 16 & 22 & 38 & 14.4 \\
Typhoid perforation & 18 & 22 & 40 & 15.2 \\
Intestinal obstruction & 2 & 4 & 6 & 2.3 \\
Strangulated epigastric hernia & 0 & 4 & 4 & 1.5 \\
Bleeding DU & 1 & 4 & 5 & 1.9 \\
BAT with perforated viscus & 2 & 2 & 4 & 1.5 \\
Primary peritonitis & 0 & 2 & 2 & 0.8 \\
Strangulated inguinal hernia & 1 & 1 & 2 & 0.8 \\
Haemoperitonium & 0 & 1 & 1 & 0.4 \\
Septic abortion & 0 & 1 & 1 & 0.4 \\
Pulmonary embolism & 0 & 1 & 1 & 0.4 \\
Sigmoid volvulus & 0 & 1 & 1 & 0.4 \\
Acute cholecystitis & 0 & 1 & 1 & 0.4 \\
Anaemia, colonic tumour & 0 & 1 & 1 & 0.4 \\
Peritonitis & 0 & 2 & 2 & 0.8 \\
\hline Total & 95 & 169 & 264 & 100.3 \\
\hline
\end{tabular}

$\mathrm{DU}=$ Duodenal Ulcer, $\mathrm{BAT}=$ Blunt Abdominal Trauma

Table 7

Post-operative complications

\begin{tabular}{lcccc}
\hline Complication & Retrospective & Prospective & Total & $(\%)$ \\
\hline Chest infection & 3 & 18 & 21 & 6.4 \\
Septicaemia & 9 & 8 & 17 & 5.2 \\
Wound infection & 2 & 11 & 13 & 4.0 \\
Leakage & 2 & 3 & 5 & 1.5 \\
Intra-abdominal sepsis & 1 & 4 & 5 & 1.5 \\
Bleeding & 1 & 0 & 1 & 0.3 \\
Acute renal failure & 1 & 1 & 2 & 0.6 \\
Mental disturbance & 1 & 1 & 2 & 0.6 \\
Jaundice & 1 & 0 & 1 & 0.3 \\
Pedal oedema & 1 & 0 & 1 & 0.3 \\
Urethral injury & 0 & 1 & 1 & 0.3 \\
Bed sore & 0 & 1 & 1 & 03 \\
Enterocutaneous fistula & 0 & 1 & 1 & 0.3 \\
Pleural effusion & 0 & 1 & 1 & 0.3 \\
Duodenal blow-out & 0 & 1 & 1 & 0.3 \\
Acute urine retention & 0 & 1 & 1 & 0.3 \\
Aspiration pneumonitis & 0 & 1 & 1 & 0.3 \\
\hline Total & 22 & 53 & 75 & 22.6 \\
\hline
\end{tabular}


Logistic regression analysis, on 254 patients whose complete medical records were available and who underwent surgery, of the factors that influenced the development of complications showed that age less that 60 years, $\mathrm{p}$-value $=0.002,(\mathrm{OR} 3.964,95 \%$ CI 1.668-9.420), duration of perforation of more than 24hours before admission, p-value $=0.011$, (OR 2.471,95\% CI 1.228- 4.971), alcohol intake, pvalue $=0.009,(\mathrm{OR} 2.543,95 \% \mathrm{Cl} 1.259-5.135)$ and resectional surgery, $p$-value $=0.000,(\mathrm{OR} 8.25 \mathrm{E}$, 95\% CI74204908.138-9162648048.1) were statistically significant (Table 9).

Table 8

Mortality

\begin{tabular}{lcccc}
\hline Cause & Retrospective & Prospective & Total & $(\%)$ \\
\hline Endotoxic shock & 11 & 10 & 21 & 6.4 \\
Severe anaemia & 1 & 3 & 4 & 1.2 \\
Respiratory failure & 0 & 5 & 5 & 1.5 \\
Liver failure & 1 & 0 & 1 & 0.3 \\
Pulmonary embolism & 0 & 1 & 1 & 0.3 \\
Hypoglycaemia & 0 & 1 & 1 & 0.3 \\
Aspiration pneumonitis & 0 & 1 & 1 & 0.3 \\
Congestive heart failure & 0 & 1 & 1 & 0.3 \\
Acute renal failure & 0 & 1 & 1 & 0.3 \\
\hline Total & 13 & 23 & 36 & 11 \\
\hline
\end{tabular}

NB: Nine patients in the prospective and one in the retrospective groups died before surgery could be undertaken

Table 9

Logistic regression analysis of complications (62 patients)

\begin{tabular}{|c|c|c|c|c|c|c|c|c|}
\hline Variable & No. & Complication & $(\%)$ & $X^{2}$ & P-value & OR & & $95 \% \mathrm{CI}$ \\
\hline \multicolumn{9}{|l|}{ Sex } \\
\hline Male & 212 & 50 & 23.6 & 0.009 & 0.923 & 1.043 & 0.444 & 2.448 \\
\hline Female & 42 & 12 & 28.6 & & & & & \\
\hline \multicolumn{9}{|l|}{ Age } \\
\hline$<60$ & 220 & 55 & 25 & 9.722 & 0.002 & 3.964 & 1.668 & 9.420 \\
\hline$\geq 60$ & 34 & 7 & 20.6 & & & & & \\
\hline \multicolumn{9}{|c|}{ History dyspepsia } \\
\hline$<3$ months & 102 & 26 & 25.5 & 0.020 & 0.887 & 1.087 & 0.344 & 3.430 \\
\hline$\geq 3$ months & 152 & 36 & 23.7 & & & & & \\
\hline \multicolumn{9}{|l|}{$\begin{array}{l}\text { Duration of } \\
\text { perforation }\end{array}$} \\
\hline$\leq 1$ & 118 & 17 & 14.4 & 6.428 & 0.011 & 2.471 & 1.228 & 4.971 \\
\hline$>1$ & 136 & 45 & 33.1 & & & & & \\
\hline \multicolumn{9}{|c|}{ Co-morbid condition } \\
\hline Yes & 46 & 23 & 50 & 0.086 & 0.769 & 0.873 & 0.353 & 2.162 \\
\hline No & 208 & 39 & 18.8 & & & & & \\
\hline \multicolumn{9}{|l|}{ NSAIDS } \\
\hline Yes & 92 & 28 & 30.4 & 0.418 & 0.518 & 1.242 & 0.643 & 2.399 \\
\hline No & 162 & 34 & 21 & & & & & \\
\hline
\end{tabular}


Table 9 continuation

Alcohol

\begin{tabular}{|c|c|c|c|c|c|c|c|c|}
\hline Yes & 124 & 36 & 29 & 6.775 & 0.009 & 2.543 & 1.259 & 5.135 \\
\hline No & 130 & 26 & 20 & & & & & \\
\hline \multicolumn{9}{|l|}{ Smoking } \\
\hline Yes & 32 & 5 & 15.6 & 0.162 & 0.687 & 0.814 & 0.299 & 2.219 \\
\hline No & 222 & 57 & 25.7 & & & & & \\
\hline \multicolumn{9}{|l|}{ Pulse } \\
\hline$<90$ & 99 & 21 & 21.2 & 0.043 & 0.835 & 1.076 & 0.540 & 2.143 \\
\hline$\geq 90$ & 155 & 41 & 26.5 & & & & & \\
\hline \multicolumn{9}{|l|}{$\mathrm{Hb}$} \\
\hline$<10$ & 30 & 10 & 33.3 & 0.380 & 0.538 & 0.728 & 0.265 & 2.001 \\
\hline$\geq 10$ & 224 & 52 & 23.2 & & & & & \\
\hline \multicolumn{9}{|l|}{ BP (Systolic) } \\
\hline$<100$ & 34 & 13 & 38.2 & 3.590 & 0.058 & 0.423 & 0.173 & 1.030 \\
\hline$\geq 100$ & 220 & 49 & 22.3 & & & & & \\
\hline \multicolumn{9}{|l|}{ Site of perforation } \\
\hline Duodenal & 223 & 48 & 21.5 & 2.704 & 0.100 & 2.231 & 0.857 & 5.805 \\
\hline Gastric & 31 & 14 & 45.2 & & & & & \\
\hline \multicolumn{9}{|l|}{ Operation } \\
\hline Simple closure & 243 & 57 & 23.5 & 279.2 & 0.000 & 8.25.E+ & 7920490 & 916264 \\
\hline & & & & 32 & & 08 & 8.138 & 8048.1 \\
\hline TV\& DR & 7 & 2 & 28.6 & & & & & \\
\hline Gastrectomy & 4 & 3 & 75 & & & & & \\
\hline
\end{tabular}

TV \& DR= Truncal vagotomy and drainage

Table 10

Logistic regression analysis of mortality

\begin{tabular}{|c|c|c|c|c|c|c|c|c|}
\hline Variable & No. & Deaths & $(\%)$ & $X^{2}$ & P-value & OR & & $95 \% \mathrm{CI}$ \\
\hline \multicolumn{9}{|l|}{ Sex } \\
\hline Male & 212 & 18 & 8.5 & 1.387 & 0.239 & 2.087 & 0.613 & 7.106 \\
\hline Female & 42 & 6 & 14.3 & & & & & \\
\hline \multicolumn{9}{|l|}{ Age } \\
\hline$<60$ & 220 & 15 & 6.8 & 5.571 & 0.018 & 4.359 & 1.284 & 14.802 \\
\hline$\geq 60$ & 34 & 9 & 26.5 & & & & & \\
\hline \multicolumn{9}{|c|}{ History of dyspepsia } \\
\hline$<3$ months & 102 & 6 & 5.9 & 1.133 & 0.282 & 0296 & 0.032 & 2.722 \\
\hline$>3$ months & 153 & 18 & 11.8 & & & & & \\
\hline \multicolumn{9}{|c|}{ Duration of perforation } \\
\hline$\leq 1$ & 118 & 8 & 6.8 & 0.355 & 0.552 & 1.409 & 0.456 & 4.351 \\
\hline$>1$ & 136 & 16 & 11.9 & & & & & \\
\hline \multicolumn{9}{|c|}{ Co-morbid condition } \\
\hline Yes & 46 & 10 & 21.7 & 0.178 & 0.673 & 0.709 & 0.144 & 3.501 \\
\hline No & 208 & 14 & 6.7 & & & & & \\
\hline
\end{tabular}




\begin{tabular}{|c|c|c|c|c|c|c|c|c|}
\hline \multicolumn{9}{|l|}{ NSAIDS } \\
\hline Yes & 92 & 13 & 14.1 & 1.162 & 0.281 & 1.794 & 0.620 & 5.195 \\
\hline No & 162 & 11 & 6.8 & & & & & \\
\hline \multicolumn{9}{|l|}{ Alcohol } \\
\hline Yes & 124 & 13 & 10.5 & 4.155 & 0.042 & 3.238 & 1.046 & 10.021 \\
\hline No & 130 & 11 & 8.5 & & & & & \\
\hline \multicolumn{9}{|l|}{ Smoking } \\
\hline Yes & 32 & 0 & 0 & - & - & $\begin{array}{c}3.424 \mathrm{E}- \\
08\end{array}$ & $\begin{array}{c}3.424 \mathrm{E}- \\
08\end{array}$ & $\begin{array}{c}3.424 \mathrm{E}- \\
08\end{array}$ \\
\hline No & 222 & 24 & 10.8 & & & & & \\
\hline \multicolumn{9}{|l|}{ Pulse } \\
\hline$<90$ & 99 & 10 & 10.1 & 1.500 & 0.221 & 0.499 & 0.64 & 1.518 \\
\hline$\geq 90$ & 155 & 24 & 15.5 & & & & & \\
\hline \multicolumn{9}{|l|}{$\mathrm{Hb}$} \\
\hline$<10$ & 30 & 5 & 16.7 & 0.308 & 0.579 & 0.640 & 0.132 & 3.093 \\
\hline$\geq 10$ & 224 & 19 & 8.5 & & & & & \\
\hline \multicolumn{9}{|l|}{ BP } \\
\hline$<100$ & 34 & 7 & 20.6 & 3.198 & 0.074 & 0.310 & 0.086 & 1.119 \\
\hline$\geq 100$ & 220 & 14 & 6.4 & & & & & \\
\hline \multicolumn{9}{|l|}{ Site of perforation } \\
\hline Duodenal & 223 & 19 & 8.5 & 0.11 & 0.917 & 1.088 & 0.223 & 5.306 \\
\hline Gastric & 31 & 5 & 16.1 & & & & & \\
\hline \multicolumn{9}{|l|}{ Operation } \\
\hline \multirow[t]{2}{*}{ Simple closure } & e 243 & 21 & 8.6 & 317.993 & 0.000 & $1.20 \mathrm{E}+10$ & 938112 & $1.540 \mathrm{E}$ \\
\hline & & & & & & & 290.94 & +11 \\
\hline TV \& DR & 7 & 1 & 14.3 & & & & & \\
\hline gastrectomy & 4 & 2 & 50 & & & & & \\
\hline
\end{tabular}

TV \& DR $=$ Truncal vagotomy and drainage

Age 60 years and above, $\mathrm{p}$-value $=0.018,(\mathrm{OR} 4.359,95 \%$ CI 1.284-14.802), alcohol intake, $p$-value $=0.042$, (OR $3.238,95 \%$ CI 1.046-10.021) and resectional surgery, p-value $=0.000$, (OR 1.20E, 0.95\% CI 938112920.94$1.54 \mathrm{E}+11)$ were the only factors which were shown to be statistically significant in determining postoperative mortality (Table 10).

\section{DISCUSSION}

This study reveals that the disease afflicts the youth in Ghana, mostly males, with low socio-economic standing. Several factors could account for this: populations in the tropics are young; life expectancy in Ghana is currently 56 years for men and 61 years for women; males are confronted with stressful life activities in the face of an improving economy with few well paid jobs and heavy family responsibilities $(16,17)$, there is an increase in alcohol consumption among the youth; and a high prevalence of $H$. pylori infection in the population mainly as a result of poor environmental sanitation (18-20).

The overall incidence of perforated peptic ulcer in this study among patients with non-traumaticacute abdomen was $4.6 \%$. There was a rise in the incidence from $1998(1.6 \%)$ to $2002(5.3 \%)$ when the incidence appeared to have stabilised at about $5 \%$. There is an observed decline in the incidence of typhoid ileal perforation in recent years in the Accra metropolis. Peptic ulcer perforation may, therefore, become the second most frequent cause of peritonitis after appendicitis and its complications in time to come.

The development of the oesophago-gastroduodenoscope was a major contributor to the reduction in the incidence of peptic ulcer perforation noticed during the second half of the twentieth century. It offers timely diagnosis and treatment of ulcers in dyspeptic patients who have $H$. pylori infection. As many as $56.1 \%$ of the patients in this study did not have dyspepsia at all or had it for less than 
three months before the perforation. Even in those who had dyspepsia for more than three months, the diagnosis was confirmed endoscopically in only eight $(5.6 \%)$ of them. This picture reveals a situation where peptic ulcers may develop insidiously and progress rapidly to perforation leaving little chance for early diagnosis and prevention of subsequent perforation. The synergistic role of $H$. pylori and NSAIDS in the causation of aggressive ulcers is debatable $(21,22)$. However poor environmental sanitation, the high prevalence of $H$. pylori among dyspeptic patients in the West African sub-region (18-20), the low socioeconomic status of those affected, the young age of those affected and the predominance of duodenal perforations $(88 \%)$ are pointers to a likely high incidence of $H$. pylori infection in these patients. This together with the observed large number of patients (67\%) who were indulging in ulcerogenic substances may haveengendered the development of aggressive ulcers leading to perforation in our patients.

Duration of perforation for more than 24 hours is an independent risk factor for an adverse outcome following treatment. Reports from elsewhere indicate that about $70 \%$ of patients with peptic ulcer perforation report within a day of onset of perforation $(23,24)$. In this study $46.2 \%$ of patients reported within 24 hours, $8.7 \%$ reporting within 12 hours. Delay in referrals from primary care centres where patients were seen initially and logistical constraints may have accounted for the large number of patients seen after 24 hours of perforation in this study and might have created a selection bias in falsely placing patients in the delayed treatment group. This was a limitation since the duration of the perforation recorded in this study did not take account of the initial care at the primary care centre. Delayed treatment was a statistically significant risk factor for the development of complications, $\mathrm{p}$-value $=0.11, \mathrm{OR} 2.471,95 \% \mathrm{CI}$ 1.228-4.971, but not for mortality, p-value $=0.552$, OR $1.409,95 \%$ C1 $0.456-4.351$. At the primary care centres treatment, including intra-venous infusions, antibiotics and analgesic, is normally started. The clinical states of these patients on arrival at the tertiary centre will not be reflective of what it would have been had earlier interventions not taken place.

The prevalence of co-morbid conditions among the patients in this study was low $48(18.2 \%)$. This differs widely from the high prevalence rate $(40-50 \%)$ of co-morbid conditions in reported series from the Western world $(24,25)$. The presence and number of co-morbid conditions impact significantly on surgical outcome in patients with perforated peptic ulcer disease. Patients with hypertension, diabetes mellitus, asthma, sickle cell disease and benign prostate hyperplasia in this study were well controlled with medication and were classified as ASA 2E and the four patients who developed their perforation whilst recovering from an earlier surgery were optimised,
ASA 3E, before surgery. It is not surprising that these co-morbid conditions did not significantly impact on post-operative outcome.

Mortality rate associated with peptic ulcer perforation was $11 \%$ overall, but the post- operative mortality rate was $8 \%$. This mortality rate is higher than the $5 \%$ overall post-operative mortality rate widely published in the literature (26).

Some reports on pepticulcer perforations indicate that shock on admission is a strong determinant of mortality (20-25). Shock is a correctable variable that must be treated before surgery is performed to minimise mortality rate. What these reports have largely failed to discuss is the haemodynamic status of the patients during the peri-operative period because if shock persists at this time the risk of mortality is high. In this report both shock (systolic $\mathrm{BP}<100 \mathrm{mmHg}$ ) and anaemia $(\mathrm{Hb}<10 \mathrm{~g} / \mathrm{dl})$ on admission were not statistically significant predictors of morbidity and mortality because these deficits were always corrected before surgery. Ten patients who presented in states of irreversible shock progressed into renal failure and died without surgery.

Age 60 years and above, alcohol intake and resectional surgery to treat the perforation were factors that were statistically significant in predicting post-operative complications and/or mortality. The youth in Ghana are lured into alcohol abuse by seductive advertisements in the media. There is no strict enforcement of regulations on the purchase and / or consumption of alcoholic beverages in Ghana. This current finding of an ill effect of alcohol in the treatment of peptic ulcer perforation, therefore, adds to the tally of the harmful effects alcohol can have on the body.

Mortality following definitive surgery to treat peptic ulcer perforation could rise to $31 \%(20,24,26)$. The small number of patients who underwent resectional surgery indicates that they were specially selected and makes meaningful interpretation of these results difficult. Of the four patients who underwent partial gastrectomy two had perforated posterior duodenal ulcer associated with bleeding while the other two had their duodenal bulb destroyed by fibrosis. The reasons that guided the use of truncal vagotomy and drainage in seven patients were that these patients were young, had reported within 24 hours of perforation, were identified as persons who could not buy their drugs for $\mathrm{H}$. pylori eradication and PPI, and in some, a callus was found at the ulcer edge.

In conclusion, perforated peptic ulcer disease is emerging as a frequent cause of acute abdomen at the Korle-Bu Teaching Hospital, Accra, Ghana. Those who indulge in ulcerogenic substances, have limited income, and who are frequently without previous dyspeptic symptoms, are mostly affected. Many 
patients with perforation report late to hospital for treatment. The young age of patients presenting with perforated peptic ulcer at the KBTH was the main factor that minimised the development of adverse post-operative outcome. Hinged to this was the energetic correction of physiological, haematological and biochemical deficits that were present on admission before surgery was undertaken. Patients aged 60 years and above, alcohol intake and the use of resectional surgical technique in treatment were the main statistically significant factors that predicted morbidity and / or mortality.

\section{REFERENCES}

1. Highan, J., Kang, J- Y. and Majeed, A. Recent trends in admissions and mortality due to peptic ulcer in England:increasing frequency of haemorrhage among older subjects. Gut. 2002; 50: 460 - 464.

2. Svanes, C. Trends in perforated pepticulcer: incidence, etiology, treatment and prognosis. World. J. Surg. 2000; 24: 277-283.

3. Canoy, D.S., Hart, A. R. and Todd, C. J. Epidemiology of duodenal ulcer perforation in Norkfold, United Kingdom. Dig. Liver. 2002; 34: 322-327.

4. Svanes, C., Soreide J. A., Skarstein, A., et al. Smoking and ulcer perforation. Gut. 1997; 41: 177-180.

5. Collier, D. St J. and Pain, J.A. Non-steroidal antiinflammatory drugs and peptic ulcer perforation. Gut. 1985; 26: 379-363.

6. Madogimje, O.A. and Lawire, J. H. Surgical management of duodenal ulcer in Zaria, Nigeria. J. Roy. Coll. Surg. Edinb. 1985; 30: 283-287.

7. Otu, A. A. Prospective evaluation of simple suture in the surgical Treatment of perforated peptic ulcer. West. Afr. J Med. 1990; 9: 295-298.

8. Naaeder, S. B. and Archampong, E. Q. Clinical spectrum of acute abdominal pain in Accra, Ghana. West Afr. J. Med. 1999; 18: 13-16.

9. Ohene- Yeboah, M. Acute surgical admissions for abdominal pain in adults in Kumasi, Ghana. ANZ J. Surg. 2006; 76: 898-903.

10. Darko, R. Peritonitis and intra-peritoneal abscesses. In: Badoe E.A., Archampong E.Q., da Rocha-Afudu J.T.(Eds). Principles and practice of surgery including pathology in the tropics. Accra; University of Ghana Medical School, 2000: 509-517.

11. Marshall, B. J. and Warren, J. R. Unidentified curved bacilli in the stomach of patients with gastritis and peptic ulceration. Lancet. 1984; 1: 1311 - 1315.

12. Anda, R. F., Williamson, D. F., Escobedo, L. G., et al. Self- perceived stress and the risk of peptic ulcer disease: A longitudinal study of US adults. Arch. Intern. Med. 1992; 152: 829-833.

13. Pattern and Trends of poverty in Ghana 1991-2006. Ghana statistical service. April 2007.

14. Aduful, H.K., Naaeder, S.B., Darko, R., et al. Upper gastrointestinal endoscopy at Korle-Bu Teaching Hospital, Accra. Ghana. Ghana Med. J. 2007; 41: 12-16.

15. Ndubula, D. A., Agbakwuru, A. E., Adebayo, R. A., et al. Upper gastrointestinal findings and incidence of helicobactor pylori infection among Nigerian patients with dyspepsia. West Afr. J.Med. 2001; 20: 140-145.

16. Baako, B. N. and Darko, R. Incidence of helicobacter pylori infection in Ghanaian patients with dyspeptic symptoms referred for upper gastrointestinal endoscopy. West Afr. J. Med. 1006; 15: 223-227

17. Kim, J.G. and Graham, D.Y. Helicobacter pylori and the development of gastric or duodenal ulcer in arthritic patients receiving chronic NSAID therapy: the Misoprostol Study Group. Am. J. Gastro. 1994; 89: 203-207.

18. Taha, A. S., Sturrock, R. D. and Russell, R. I. Mucosal erosions in long term non-steroidal anti inflammatory drug users: predisposition to ulceration and relation to Helicobacter pylori. Gut. 1995; 36: 334-336.

19. Valerio, D., Hendry, W.S. and Jones, P.F. Perforated peptic ulcer in North-East Scotland 19721981: Part 2; Definitive treatment or oversew? J. Roy. Coll. Surg. Edinb. 1985; 30: 364-368.

20. Testini, M., Portincasa, P., Piccinni, G., et al.Significant factors associated with fatal outcome in emergency open surgery for perforated peptic ulcer. World J. Gastroenterol. 2003; 9: 2338-2340.

21. Noguiera, C., Silva, A.S., Santos, J. N., et al. Perforated peptic ulcer: Main factors of morbidity and mortality. World. J. Surg. 2003; 27: 782-787.

22. Gisbert, J. P. and Parajes, J. M. Helicobacter pylori infection and perforated peptic ulcer prevalence of the infection and role of Antimicrobial Treatment. Helicobacter. 2003; 8: 159-167.

23. Irvin, T.T., Mortality and perforated peptic ulcer: a case for risk stratification in elderly palients. $\mathrm{Br}$. J. Surg. 1989; 76: 215-218.

24. Evans, J. P. and Smith, R. Predicting poor outcome in perforated peptic ulcer disease. Aust. NZJ. Surg. 1997; 67: 792-795.

25. Boey, J., Choi, S. K., Poon, A. and Alagaratnam, T. T. Risk stratification in perforated duodenal ulcer: a prospective validation of predictive factors. Ann. Surg. 1987; 205: 22-26.

26. Kujath, P., Schwander and Bruch, H. P. Morbidity and mortality of perforated peptic gastroduodenal ulcer following emergency surgery. Langenbecks Arch. Surg. 2002; 387: 298-302. 